\title{
PROPHYLAXIS AND TREATMENT OF CARDIAC ARREST*
}

\author{
Guy Fortin, M.D., and RenÉ LÉtIENne, M.D., F.R.C.P.(C) *
}

COMPLETE and successful resuscitation from clinical death implies that adequate measures must be instituted during the interval of time which extends from cardiac arrest up to the moment which precedes the initial irreversible biological destruction of the cerebral tissues. This interval of time has been established experimentally by Weinberger, Gibbon and Gibbon (1) at three and one-half minutes. Clinically, it is generally agreed that this interval may extend to four minutes (2).

The most important factor which will influence the viability of tissues following cardiac arrest is the degree of oxygen reserve in the tissues at the time of the arrest. If through negligence or uncontrollable circumstances resuscitative measures are instituted after the four-minute time limit, the situation is still not hopeless provided the patient was well oxygenated at the time of the arrest regardless of its cause.

\section{Causes of Cardiac Arrest}

In order to institute proper prophylactic measures and treatment, it is essential to be familiar with the common causes of sudden cardiac failure.

Since cardiac arrest may occur as a result of either surgical or anaesthetic factors, we shall consider these separately.

\section{Cardiac Arrest of Surgical Origin}

Vago-vagal reflexes have an inhibitory influence on the intrinsic conductive mechanism of the heart. This may lead to cardiac standstill when the specific tissue in the heart is depressed by anaesthesia (3). Vagal inhibitory activity may occur during intra- or extrathoracic manipulations such as rib stripping and retraction, pleural incision, traction and clamping of pulmonary hilar structures, dissection of pulmonary artery or aorta and direct vagal stimulation. Abdominal visceral and mesenteric traction, and irritation of a hypersensitive carotid sinus may also lead to asystole through the same mechanism. Concomitant hypoxia greatly lowers the resistance of the heart against these inhibitory reflexes (4).

Mechanical compression of the heart and great vessels during direct manipulation or by retractors interferes with cardiac activity and is a real hazard.

Air embolism may occur when the posture of the patient favours a negative venous pressure at the site of the operation. This condition is fulfilled during neurosurgical operations performed in the sitting position or in pelvic operations with the patient subjected to a steep Trendelenburg inclination. In either situation, a medium-sized vein, left open, will allow air to be aspirated (5).

Surgical and haemorrhagic shock, if not controlled, may lead to cardiac arrest due to stagnant hypoxia.

'Presented before the Sectional Meeting, American College of Surgeons, Montreal, April 1, 1954.

* Department of Anesthesia, Queen Mary Veterans Hospital. 


\section{Cardiac Arrest due to Anaesthetic Causes}

Increase in cardiac irritability by sensitization to adrenalin either of endogenous or exogenous origin may occur with cyclopropane, trichlorethelene, ethyl chloride and chloroform. If proper prophylactic measures and adequate selection of anaesthetic agents are not respected arrhythmias may occur and progress to ventricular fibrillation and arrest.

Vago-vagal and vago-sympathetic (6) reflexes are prone to occur with currently used anaesthetic procedures. When highly reflexogenic zopes of the trachea and bronchi are irritated by the insertion of an endotracheal airway, by a sudden high concentration of an irritant anaesthetic agent, or by bronchial aspiration, inhibitory reflexes may occur and lead to asystole. Pentothal potentiates vagal activity and serious cardiac inhibitory reflexes may occur when it is used for certain surgical procedures on the neck.

Anaesthetic overdosage may lead to myocardial depression and arrest. Usually the condition sets in gradually and for this reason is easily diagnosed before it produces asystole.

Neurogenic spinal shock places a great strain on the heart. A high spinal anaesthesia which goes beyond the safe limit of spontaneous physiological reserve not artificially compensated may lead rapidly to myocardial ischaemia and cardiac arrest. There is widespread sympathetic paralysis involving the cardiac accelletor nerves. Combined with predominant vagal activity, this leads to stagnant hypoxia. The heart cannot withstand the added strain of anoxic hypoxia from respiratory paralysis.

Other causes of anoxia or asphyxia threaten the heart of the patient. Excessive premedication, respiratory obstruction, inadequate blood replacement, improper management of controlled or assisted/respiration in deep anaesthesia or in curarized patients may all lead to cardiac ischaemia. Anoxia superimposed on a heart already depressed by anaesthetic agents decreases the capacity of the specific tissue to form stimuli. Under such conditions the heart becomes vulnerable to vago-vagal reflexes (3). In cardiac arrest associated with hypoxia the prognosis is very severe. Irreversible damage to the brain and heart may have occured even before resuscitative measures are instituted.

Intolerance to local anaesthetic drugs may result in cardiac arrest either by central cardiovascular depression or by direct depression of the myocardium (7).

\section{Prophylaxis of Cardiac Arrest}

\section{Surgical Prophylaxis}

Close collaboration between surgeon and anaesthetist must exist at all times.

With regard to vago-vagal reflexes, undue traction on thoracic or abdominal viscera should be avoided. Exteriorization of organs should be performed gradually. Infiltration of hyperactive areas with procaine before manipulation will avoid serious trouble. The position of retractors should be checked often and should not interfere with cardiac activity.

If the surgeon's attempt to accomplish a technical masterpiece be detrimental to the patient, he must sacrifice quality for efficiency and expediency in his work.

In all cases of direct intervention on the heart, the surgeon should insist on 
a continuous or intermittent electrocardiographic record with a responsible person in attendance capable of interpreting the results (8). The surgeon must make certain that reflex activity is sufficiently obtunded before starting the incision.

Adrenalin-soaked sponges and packs should not be used without the knowledge of the anaesthetist. Whenever necessary the anaesthetist will oblige by changing to another compatible agent.

Excessive bleeding must be avoided.

\section{Anaesthetic Prophylaxis}

Here again mutual respect, perfect understanding and close co-operation amongst members of the surgical team are prerequisites if cardiac emergencies are to be avoided during all major operations. At no time should relations between surgeon and anaesthetist be strained. The surgeon should realize that there are legitimate reasons for slow, difficult anaesthetic procedures just as there are reasons for slow, tedious surgical work. Let it be understood that the anaesthetist is working primarily for the patient. He resents order-like requests devoid of scientific reasoning. Under tense working conditions the one to falter is not always the anaesthetist. Indeed courtesy plays an important role in prophylaxis of cardiac arrest.

The most important prophylactic means of preventing cardiac emergency is adequate oxygenation. It is the anaesthetist's duty to keep the highest possible oxygen concentration in the tissues of his patient provided the surgeon will not interfere by his exigencies. So called ideal operating conditions necessitating protracted periods of apnoea or depressed breathing are a hazard to any patient and are to be deplored. For intrathoracic procedures, intermittent oxygenation is not enough and indeed the intervals of apnoea to provide adequate facilities for surgery produce periods of anoxia which have cumulative deleterious effects upon the heart muscle and specific tissue. Uninterrupted controlled or assisted respirations, so valuable to the patient, are actually an advantage to the surgeon. Regardless of lung retraction, efficient tidal air is maintained by overdistention of non-restrained pulmonary tissue. Paradoxical respiration, often fatal to patients, is suppressed, which, for the surgeon, means absence of annoying excessive diaphragmatic activity and mediastinal shifting. In present-day anaesthesia, the patient must be well "coloured" at all times so that different shades of cyanosis should never be a criteria for the degree of tolerance to anoxia (9).

Impending cardiac arrest is often preceded by predominant vagotonic effects manifested by bradycardia and lowering of blood pressure. Simultaneously, displacement of the pacemaker and appearance of ventricular premature beats may occur (8). At such a time the patient should be well oxygenated and atropine given intravenously in appropriate dosage. Reid (3) considers atropine one of the most valuable drugs to prevent cardiac arrest during the course of general anaesthesia. It blocks the interference with stimulus formation in the auricles.

For intrathoracic procedures, it has been our impression that a continuous intravenous infusion of procaine helps to protect the heart from sudden vagal inhibition. Small quantities are administered to avoid undue depression of the myocardium and of the autonomic functions of the heart. Usually not more than 
one gram of 0.2 per cent solution in 5 per cent glucose is administered during the course of an intrathoracic operation on an adult patient. For some time we have been using Largactyl (chlorpromazine) instead of procaine. This drug appears to give protection to the heart; however it is too early for us to fully appraise its value in this regard, our clinical and laboratory investigations being as yet incomplete.

\section{Diagnosis of Sudden Cardiac Famure}

\section{Role of the Anaesthetist}

In extrathoracic operations rapid and early diagnosis of sudden cardiac failure is the most important responsiblity of the anaesthetist if resuscitation is to succeed and if the patient is to remain free from neurologic complications. Delay in diagnosis is the chief cause of failure. Time-consuming diagnostic procedures such as taking blood pressure or listening for heart sounds must be excluded. The following clinical signs of cardiac arrest or fibrillation require only a few seconds to ascertain and their presence should bring an immediate request to the surgeon to start resuscitation: imperceptible peripheral pulse; dilated pupils, the degree of dilatation varying with the degree of anoxia and depth of anaesthesia at the time of the arrest and elapsed time between arrest and diagnosis; ashen grey colour of the skin; pallor or cyanosis; sighing respiration or apnoea, depending on depth of anaesthesia and absence or presence of curarization. If respirations are still active at the time of arrest, ideally, diagnosis should be established before subsequent appearance of apnea.

When the site of operation favours a negative pressure in the exposed veins, sudden cardiac failure points to gas embolus unless another mechanism is plainly evident.

It must be recognized that apnea and imperceptible peripheral pulse do not imply cardiac arrest and do not necessitate extreme resuscitative manoeuvres if other signs are not present. Should spontaneous respiratory activity cease at a time when cardiac function appears to be at a standstill, the administration of pure oxygen by means of controlled respiration will not only serve as a diagnostic procedure but also as a therapeutic measure. This necessary procedure will determine the efficiency of residual cardiac activity if present and rule out cardiac arrest by maintenance of a good colour in the patient. Operative procedure should not be resumed until blood pressure is adequate as determined by the anaesthetist.

\section{Role of the Surgeon}

When the thorax is open direct visualization and palpation of the heart confirms the diagnosis.

When the abdomen is opened, verification of diagnosis is obtained by palpating the heart from below the diaphragm or the abdominal aorta.

In extrathoracic and extraabdominal operations where the surgeon is not in a position to feel the heart or a large artery, palpation of the heart through an opening in the left chest wall is the only positive diagnostic procedure. When the patient's appearance has obviously and suddenly deteriorated to a death-like 
state there is no time for consultation or meditation. Stethqscopes and ophthalmoscopes will not save the patient at this stage (10).

When an electrocardiogram machine is already in operation, there is no problem as to the state of cardiac activity or inactivity. However fibrillation does not exist, there is no way of telling whether residual cardiac action is efficient or not. If usual remedial measures do not re-establish a palpable pulsation within a few seconds, cardiac massage must be instituted.

\section{Treatment of Cardiac Arrest}

\section{Role of the Anaesthetist}

As soon as cardiac arrest is assumed, or definitely established, all gaseous or volatile anaesthetics must be eliminated from the breathing bag and oxygen delivered to the patient. If the patient is not already intubated, artificial respiration must begin at once with the mask.

A five-degree head-down position will help irrigate the nervous centres.

A transfusion will contribute to the maintenance of an adequate peripheral circulation and will increase venous return.

\section{Role of the Surgeon}

It should not appear strange for the anaesthetist to discuss the role of the surgeon in cardiac resuscitation. There are occasions where the anaesthetist himself must perform cardiac massage.

If sudden failure of the heart to maintain circulation occurs during an intrathoracic operation, massage must be started at once.

When the abdomen is open, subdiaphragmatic or transdiaphragmaticcardiac massage may be attempted as a means of stimulating the heart into activity rather than as a means of producing efficient circulation. Thoracotomy is the method of choice.

In extrathoracic and extraabdominal operations valuable time must not be lost in preliminary attempts at resuscitation. These attempts are simple manoeuvres such as strenuous thumping and application of hot packs over the precordial region; transthoracic needle puncture of the heart to produce mechanical stimulus or to inject drugs directly into the heart chambers; indirect cardiac massage over the left hypochondrium. One, and only one of these procedures may be attempted by the surgeon with his left hand while his right hand is reaching for the knife. These procedures will not cause a heart in ventricular fibrillation to revert to a normal rhythm. Cardiac massage via thorocotomy should not be withheld as a last resort when all else has failed (11).

A rapid rate of massage seems to give a greater flow of blood and does not appear to interfere with ventricular filling (12). If necessary, the pericardium may be opened to improve massage.

To shunt more blood into the coronary and cerebral circulation, the aorta should be compressed just below the origin of the left subclavian artery during massage. It follows that great care must be taken not to obstruct the coronary vessels.

Since there is absence of adequate coronary blood flow during fibrillation, 
cardiac massage must precede defibrillation (13). Only then can serial electric shock defibrillation (14) be attempted. Otherwise the heart will not be ready to respond by massage following electrical arrest. Occasionally, ventricular fibrillation may revert to a normal rhythm by massage alone (15).

The treatment of gas embolus requires the application of a simple manoeuvre conceived experimentally by Durant, Long and Oppenheimer (16) and-subsequently attempted with success on humans by Hamby and Terry (17). It consists in placing the patient in the left lateral position. If this does not restore a normal heart beat, needle puncture of the right ventricle should be performed in an attempt to aspirate the air therein. If this fails a rapid thoracotomy and aspiration of air under direct vision should be attempted by the surgeon. If the heart remains stationary after aspiration, massage should be instituted.

\section{The Control of Adequate Cardiac Massage}

Cardiac massage will not produce an efficient artificial circulation unless it develops a palpable peripheral pulse and raises blood pressure to a level of 70 to 80 millimetres of mercury, synchronized with each passive systole. The immediate physiological response to efficient massage should be a reduction in mydriasis and improvement in the color of the patient, provided artificial respiration is effective.

When these conditions are realized, the time will be opportune for the anaesthetist to insert an endotracheal tube. This will prevent aspiration of air into the stomach and insure a clear airway.

Artificial respiration should continue until the return of a spontaneous and adequate respiration.

Massage should continue as long, as it appears adequate and pupils are not fully dilàted.

\section{The Use of Drugs in Cardiac Arrest}

We have already said a few words with regard to the prophylatic use of drugs.

The audacity and impulsiveness that seem to govern the injection of drugs directly into the heart chambers appear to originate from the impression that sustained cardiac massage will, in itself, prevent spontaneous recovery.

It is our sincere opinion that drugs, associated with massage, are more often responsible than massage alone for preventing return of spontaneous heart beat. Although we are not prejudiced against the use of drugs in cardiac arrest, we have purposely omitted discussion of their therapeutic use to emphasize our contention that they are the least important items in the treatment of cardiac arrest. Indeed mechanical and electrical means of cardiac resuscitation are gradually acquiring precedence over drug therapy. Although there is much room for improvement, great strides are being made as already evidenced by the electronic artificial pacemaker which has opened the possibility of successful simplified cardiac resuscitation.

\section{SUMMARY}

After reviewing the main surgical and anaesthetic causes responsible for 
sudden cardiac failure during surgery, prophylactic measures to prevent it are outlined.

Methods of diagnosis and procedures in treatment are suggested. Those will usually lead to successful resuscitation from clinical death, provided they are applied efficiently and diligently. Ill-timed use of drugs and hesitant attempts to restart a powerless heart are to be deplored.

Better results are obtained only when close co-operation exists between surgeon and anaesthetist.

\section{RÉSUMÉ}

' Un arrêt cardiaque en cours d'opération, quelqu'en soit la cause, peut être traité avec succès, sans séquelles, si l'intervalle de temps entre la cessation clinique des battements et de leur retour effectif ne dépasse pas environ quatre minutes.

Les manipulations chirurgicales, le choc, l'hémorragie, l'excitation de zônes réflexogênes, la dépression respiratoire, l'hypoxie, certains agents anesthésiques et bien d'autres facteurs peuvent être incriminés. Connaissant ainsi de nombreux éléments qui mènent à un arrêt cardiaque, tous les moyens de les éviter doivent être mis en cuvre. Ceci exige une collaboration constante et soignée de la part du chirurgien et de l'anesthésiste, qui travailleront de concert pour d'abord protéger le malade, chacun contribuant selon ses moyens, sans tenter de prouesses d'une valeur douteuse. Une oxygénation tissulaire aussi saturée que possible doit toujours être de rigueur.

L'arrêt du cour impose un diagnostique immédiat, précis et son traitement doit éliminer une thérapeutique hésitante, sinon nuisible. La pulpart des drogues et les demi-mesures sont surtout à écarter. Le massage du cœur, par voie immédiate, et l'oxygénation au niveau pulmonaire constituent les éléments essentiels de la réanimation si l'on peut espérer en tirer un résultat satisfaisant.

\section{REFERENCES}

1. Weinberger, L. W., Gibbon, M. H. and Grbbon, J. H. Temporary Arrest of the Circulation to the Central Nervous System. Arch. Neurol. \& Psychiat. 43: 615-634 (1940).

2. Stephenson, H. E., Reid, L. C. and Hinton, J. W. Some Common Denominators in 1200 Cases of Cardiac Arrest. Ann. Surg. 137:731-744 (1953).

3. Rem, L. C., Stephenson, H. E. and Hinton, J. W. Cardiac Arrest. Arch. Surg. 64:409-420 (1952).

4. Sloan, H. E. The Vagus Nerve in Cardiac Arrest: Effect of Hypercapnia, Hypoxia and Asphyxia on Reflex Inhibition of Heart. Surg., Gynec. \& Obst. 91: 257-264 (1950).

5. BonicA, J. Role of Anesthesiologist in Management of Cardiac Arrest. Anesth. \& Analg. 31: 1-18 ( 1951 ).

6. Burstenn, C. L., Lo Pento, F. J. and Newman, W. Electrocardiographic Studies during Endotracheal Intubation; Effects during Normal Routine Techniques. Anesthesiology 11: 224-237 (1950).

7. Sadove, M. S., Wyant, G. M., Gittleson, L. A. and Kretchmer, H. E. Classification and Management of Reactions to Local Anesthetic Agents. J.A.M.A. 148:17-22 (1952).

8. Jaruszewskr, E. J., Helrerstein, H. K. and Frex, H. Electrocardiographic Studies during Cardiac Surgery. Circulation 7:175-191 (1953).

9. Lonfan, P. H. and Wricht, E. M. Operating Room Emergencies; Their Prevention and Management. Anesth. \& Analg. 31:423-429 (1952).

10. Johnson, J. and KIRBY, C. K. Prevention and Treatment of Cardiac Arrest. J.A.M.A. 154:291-294 (1954). 
11. Cowan, K. A. The Management of Primary Cardiac Arrest under Anesthesia. Anesth. \& Analg. 32:286-288 (1953).

12. Johnson, J. and KIRBY, C. K. An Experimental Study of Cardiac Massage, Surgery 26:472-478 (1949).

13. Wiggers, C. J. Defibrillation of the Ventricles (Editorial). Circulation Research 1:191-199 (1953).

14. - - The Physiologic Basis for Cardiac Resuscitation from Ventricular Fibrillation, Method for Surgical Defibrillation. Am. Heart J. 20:413 (1940).

15. LeEds, S. E. Cardiac Resuscitation. J.A.M.A. 152:1409-1413 (1953).

16. Durant, T. M., Long, J. and Oppenhemer, M. J. Pulmonary (Venous) Air Embolism. Am. Heart J. 33:269-281 (1947).

17. Hamby, W. B. and Terry, R. N. Air Embolism in Operations done in the Sitting Position. Surgery $31: 212-215$ (1952). 